\title{
Evaluation of hearing status after type I tympanoplasty
}

\author{
Mashuque Mahamud ${ }^{1}$, Mani Lal Aich ${ }^{2}$, Abdullah Al Mamun ${ }^{3}$, Rafiul Alam \\ Abstract \\ Objective: To evaluate hearing outcome after type I tympanoplasty in inactive mucous type of chronic \\ otitis media.
}

Methods: It was a cross-sectional study conducted in the department of Otolaryngology \& Head Neck Surgery, Sir Salimullah Medical College and Mitford Hospital, Dhaka, from July 2014 to June 2016. 50 cases were selected by matching inclusion and exclusion criteria. Paired t-test and $Z$ test was used to analyze the variables. $P$ values $<0.05$ was considered as statistically significant.

Results: The mean age was found 28.5 years with range from 15 to 41 years and male female ratio was 1.3:1. All patients had intermittent otorrhoea and varying degree of hearing loss. The mean air conduction threshold was $40.2 \mathrm{~dB}$ preoperatively and $27.1 \mathrm{~dB}$ post-operatively. Air-bone gap was found $26.9 \mathrm{~dB}$ in preoperative and $16.1 \mathrm{~dB}$ in post-operative group. The differences were statistically significant between preoperative and post-operative group. Thus mean improvement of air conduction threshold was $13.1 \mathrm{~dB}$ and air-bone gap was $10.8 \mathrm{~dB}$. Two third (66.\%) patients improved $<15 \mathrm{db}$ air conduction thresholds and $17(34 \%)$ improved $\geq 15 \mathrm{db}$ air conduction thresholds. Using the proportion of patients with a postoperative hearing within $40 \mathrm{~dB}$ as the criterion, this study showed $46(92 \%)$ patients achieving this and $40(80 \%)$ patients achieving $A B$ gap within $20 \mathrm{db}$ postoperatively.

Conclusion: Improvement of air conduction threshold and AB gap after type I tympanoplasty was statistically significant. Thus from this study it can be concluded that type I tympanoplasty is an effective technique for hearing improvement in inactive mucous type of chronic otitis media.

Key words: Inactive mucous type of chronic otitis media, type I tympanoplasty \& hearing improvement.

1. Junior Consultant (ENT), National Institute of ENT, Tejgaon, Dhaka

2. Professor and Head of the Department of ENT, Sir Salimullah Medical College \& Mitford Hospital, Dhaka

3. Junior Consultant (ENT), General Hospital, Narayanganj

4. Registrar, Department of ENT, Sir Salimullah Medical College \& Mitford Hospital, Dhaka.

\section{Address of Correspondence:}

Dr Mashuque Mahamud, Junior Consultant (ENT), National Institute of ENT, Tejgaon, Dhaka, mail: mashuque28mahmud@gmail.com, mobile: 01916519250

\section{Introduction}

Hearing is an essential requirement of an individual to perform daily activities. Deafness and hearing impairment is reported to be increasing globally, becoming one of the most frequent sensory deficits in human beings ${ }^{1}$.
According to $\mathrm{WHO}$, it is "easily overlooked and underestimated" because it is not as "dramatic" as other health care conditions. It is therefore not surprising that hearing loss has been referred to as a silent epidemic ${ }^{2}$. The problem is disproportionately high in the South-East Asia ${ }^{3}$. Eighty percent of deaf and hearing-impaired people live in low and middle-income countries 
where services are either totally absent or very limited ${ }^{4}$.

The major preventable cause of hearing impairment in low and middle-income countries is middle ear infections. The burden of otitis media occurs overwhelmingly in the developing world with almost nine times more cases reported compared to developed countries ${ }^{5}$. The poor living standard, overcrowding, lack of personal hygiene, malnutrition, smoking, lack of health education, bottle feeding in supine position, repeated upper respiratory tract infection of viral origin and lack of access to healthcare all have been suggested for the wide spread prevelance of chronic otitis media in developing countries ${ }^{6,7}$. Chronic otitis media (COM) may be divided into mucosal and squamosal variety. Both of these are further divided into active and inactive type. Among these types mucosal variety is the commonest ${ }^{8}$. Mucous type of chronic otitis media is characterized by perforation in the pers tensa of varying size and shape. It is usually associated with aural discharge and hearing loss. A perforation in the tympanic membrane reduces the effective area of the membrane in contact with the sound wave. Perforation also reduces the pressure difference across the tympanic membrane and depending on their position, reduces the mechanical coupling between the remaining intact portions of the tympanic membrane and the malleus and thus hearing loss occurs ${ }^{8}$. Hearing loss is one of the cardinal symptoms in COM which is conductive in nature, although sensorineural hearing loss may occur. The degree of hearing loss is influenced by the size and site of perforation and condition of ossicular chain but other important factors such as the presence of granulation tissue, mucous adhesion, tympanosclerosis and eustachian tube function are also of importance in determining the hearing level ${ }^{9}$.

When presenting with an inactive mucous type of chronic otitis media, one receives type I tympanoplasty procedure, to seal the eardrum. Type I tympanoplasty refers to the grafting of the tympanic membrane without reconstruction of the ossicular chain ${ }^{10}$. The concept of surgical repair of tympanic membrane was first introduced by Berthold in 1878, whereby a thick skin graft by overlay technique was used. Wullstein and Zollner used the split skin grafts. In the 1960s and 1970s, homograft (cadaveric) materials, including tympanic membrane, dura, and pericardium, among others, were used with varying success ${ }^{11}$. Since then, over the period of many decades, different grafts and techniques evolved and tympanoplasty has gone through many changes in technique and materials. Temporalis fascia continues to be the material of choice for reconstruction of the tympanic membrane ${ }^{11}$.

Three principal indications for surgery in inactive mucous type of chronic otitis media have been documented (a) prevention of recurrent otorrhoea, (b) to improve the conductive hearing loss and (c) desire to swim without wearing water proof material in the ear ${ }^{10}$. The classification of tympanoplasty related to ideal and theoretical postoperative hearing outcomes, based on middle-ear mechanics, consists of five types, each of which is based on the most lateral intact structure that remains connected to the inner ear ${ }^{12}$. For the purpose of the current study type I tympanoplasty was investigated.

Thus the current study aimed to evaluate hearing after outcome type 1 tympanoplasty.

\section{Methods}

This Cross-sectional study was conducted in the department of Otolaryngology \& Head Neck Surgery, Sir Salimullah Medical College and Mitford Hospital, Dhaka from July 2014 to June 2016. Study population included the patients of any age and sex who had undergone type I tympanoplasty.

A total of 50 patients were included in this study. The assessment of the patient was established on the basis of history, clinical examination, radiological examination and pure tone audiometry. Majority of the patients were operated on under local anaesthesia and rests were on under general anaesthesia. After postauricular 
incision, temporal fascia graft by underlay technique was used for all of the cases.

After 3 months pure tone audiometry was performed according to ISO standard. The hearing thresholds were measured at 500 , 1000 \& $2000 \mathrm{~Hz}$. Air and bone conduction thresholds was determined with appropriate masking technique throughout.
After taking informed written consent data were collected in a data collection sheet for each of the patient. Statistical analyses were carried out by using the Statistical Package for Social Sciences (SPSS) version 20. Quantitative observations were indicated by frequencies and percentages. The mean values were calculated for continuous variables. Paired t-test and $\mathrm{Z}$ test was used to analyze the continuous variables. $P$ values $<0.05$ was considered as statistically significant.

\section{Results}

Table I: Distribution of respondents by presenting complaints $(n=50)$

\begin{tabular}{|l|c|c|}
\hline Presenting complaints & Number & Percentage \\
\hline Intermittent otorrhoea & 50 & 100 \\
\hline Deafness & 50 & 100 \\
\hline Headache & 6 & 12 \\
\hline Tinnitus & 4 & 8 \\
\hline
\end{tabular}

Table II: Comparison between preoperative and postoperative hearing status $(n=50)$

\begin{tabular}{|l|c|c|c|}
\hline Pure tone audiometry & Preoperative & Postoperative & P value \\
\hline Bone conduction threshold(dB) & 13.3 & 11.1 & 0.001 \\
\hline Air conduction threshold $(\mathrm{dB})$ & 40.2 & 27.1 & 0.001 \\
\hline Air-bone gap $(\mathrm{dB})$ & 26.9 & 16.1 & 0.001 \\
\hline
\end{tabular}

$P$ value reached from paired t-test

Mean improvement of air conduction threshold was $13.1 \mathrm{~dB}$ and air-bone gap was $10.8 \mathrm{~dB}$.

Table III (a): Improvement of hearing status after type I tympanoplasty $(n=50)$

\begin{tabular}{|c|c|c|}
\hline Gain of air conduction threshold (db) & Number & Percentage \\
\hline$<15$ & 33 & 66 \\
\hline$\geq 15$ & 17 & 34 \\
\hline
\end{tabular}

Table III (b): Improvement of hearing status after type I tympanoplasty $(n=50)$

\begin{tabular}{|l|c|c|c|c|c|}
\hline \multirow{2}{*}{ Hearing status } & \multicolumn{2}{|c|}{ Preoperative } & \multicolumn{2}{c|}{ Postoperative } & \multirow{2}{*}{ P value } \\
\cline { 2 - 5 } & $\mathbf{n}$ & $\mathbf{\%}$ & $\mathbf{n}$ & $\mathbf{\%}$ & \\
\hline $\begin{array}{l}\text { Air conduction threshold } \\
\text { within 40 dB }\end{array}$ & 31 & 62.0 & 46 & 92.0 & 0.001 \\
\hline Air-bone gap within $20 \mathrm{~dB}$ & 11 & 22.0 & 40 & 80.0 & 0.001 \\
\hline
\end{tabular}

$P$ value reached from $Z$-test

\section{Discussion}


This study showed that majority (46\%) of the patients belonged to age 21-30 years. The mean age was found 28.5 years with range from 15 to 41 years. Biswas et al. found the age of the youngest patient was 12 year and age of the oldest patient was 46 years with mean age was 29 years $^{14}$. Islam et al. and Alam et al. found age varied from 15 to 45 years with a mean age of 27 years and $15-45$ years with highest number of patients was in the age group of 15-25 years respectively, which are closely resembled with the present study ${ }^{15,}{ }^{16}$. Similarly, Joshi et al. study found lowest and highest age of patients at presentation was 12 and 42 years respectively with a mean age of 25.5 years ${ }^{11}$. Similar observations regarding the age ranged were also observed by Shetty and Krishna and Devi ${ }^{17,18}$.

Among 50 patients, twenty eight (56\%) patients were male and $22(44 \%)$ patients were female. Male female ratio was 1.3:1. Similarly, male predominant also found by Islam et al. and Sarker et al. where the authors found the male to female ratio were $1.5: 1$ and 3:2 respectively ${ }^{15}$, 19. On the other hand Shetty and Krishna and Devi found female predominant in their respective studies ${ }^{17,18}$.

In this current study it was observed that all $(100.0 \%)$ patients had intermittent otorrhoea and deafness but only $6(12.0 \%)$ had headache and $4(8.0 \%)$ had tinnitus. Alam et al. found the major symptoms of their study were intermittent otorrhoea $(96.67 \%)$ and hearing loss $(90.0 \%)^{16}$. Shetty found the commonest presenting complaints are ear discharge and hearing loss seen in all the $100 \%$ patients, tinnitus is found in $18 \%$, pain in the ear in $24 \%$ and vertigo in $6 \%$ of patients ${ }^{17}$.

In this present study it was observed that air conduction threshold was found $40.2 \mathrm{~dB}$ preoperatively and $27.1 \mathrm{~dB}$ post-operatively \& $A B$ gap was found $26.9 \mathrm{~dB}$ preoperatively and $16.1 \mathrm{~dB}$ post-operatively. The differences were statistically significant between preoperative and post-operative groups. Biswas et al. found the mean pre and postoperative air conduction threshold in the successful cases were $34 \mathrm{~dB}$ and $24 \mathrm{~dB}$ respectively, with a mean audiological improvement of $10 \mathrm{~dB}$ \& improvement of mean air bone gap was $11 \mathrm{~dB}^{14}$. Lee et al. and Palva and Ramsay stated that mean hearing improvement was $8 \mathrm{~dB}$ in their series $^{20,21}$. In another study Alam et al. showed the mean pre and post operative air conduction threshold in the successful grafting cases were $31.43 \mathrm{~dB}$ and $21.43 \mathrm{~dB}$ respectively with a mean audiological improvement of $10 \mathrm{~dB}$ \& improvement of mean air bone gap was 10.83 $\mathrm{dB}^{16}$.

Islam et al. found the mean pre and post operative air conduction threshold in the successful grafting cases were $44.5 \mathrm{~dB}$ and 35.1 $\mathrm{dB}$ respectively with a mean audiological improvement of $9.4 \mathrm{~dB}$ \& improvement of mean air bone gap was $10.1 \mathrm{~dB}^{15}$. Similarly, Joshi et al. found the mean pre and post-operative air conduction threshold in the successful cases were $38.69 \mathrm{~dB}$ and $30.35 \mathrm{~dB}$ respectively with a mean audiological improvement of $8.34 \mathrm{~dB}$ \& improvement of air bone gap was $10 \mathrm{~dB}^{11}$. Above findings are similar to or lower from the current study. But few studies showed greater improvement than this study, such as Shetty observed $18.8 \mathrm{~dB}$ hearing improvement and Mehta et al. showed the average improvement of air-bone gap was $13 \mathrm{~dB}^{17,22}$. Sarker et al. and Vaiday et al. also found greater improvement than the present study ${ }^{19,23}$.

In this study it was observed that two third (66\%) patients improved $<15 \mathrm{db}$ air conduction threshold and $17(34 \%)$ improved $\geq 15 \mathrm{db}$ air conduction threshold. Shrestha and Sinha found, $39(78 \%)$ patients had their hearing gain exceeding $15 \mathrm{~dB}^{24}$. Biswas et al. study showed hearing gain occurred in $31(60.78 \%)$ patients and no improvement seen in 20 (39.21\%) patients when gain of $10 \mathrm{~dB}$ or more was considered significiant ${ }^{14}$. Joshi et al. found that hearing gain occurred in 29 ears $(67.44 \%)$ and no improvement seen in $14(32.56 \%)$ ears ${ }^{11}$. Mehta et al. observed $62 \%$ of the total cases that underwent type I tympanoplasty showed a 
gain of $>10 \mathrm{~dB}^{22}$. The above findings are consistent with the current study.

Regarding air conduction threshold within $40 \mathrm{db}$, was found $31(62 \%)$ patients in preoperative and $46(92 \%)$ in postoperative \& $A B$ gap within $20 \mathrm{db}$ was found $11(22 \%)$ in preoperative and 40 $(80 \%)$ in postoperative. The differences were statistically significant compared between preoperative and postoperative groups. Using the proportion of patients with a postoperative hearing within $40 \mathrm{~dB}$ as the criterion, Shrestha and Sinha study showed, $100 \%$ of patients achieved their hearing level within $40 \mathrm{~dB}$ and using postoperative air-bone gap within $20 \mathrm{~dB}$ as the criterion, $41(84 \%)$ patients had their airbone gap within $20 \mathrm{~dB}^{24}$. Palukuri et al. showed that $100 \%$ patients achieving air bone gap within $20 \mathrm{~dB}$, although $20 \%$ patients had air bone gap $>20 \mathrm{~dB}$ preoperatively ${ }^{25}$. Shetty showed that $19(38 \%)$ patients had air conduction threshold within $40 \mathrm{~dB}$ preoperatively but $100 \%$ postoperatively ${ }^{17}$.

\section{Conclusion}

Hearing loss is one of the most common presenting complaints in the chronic otitis media patient. There is no significant male female ratio. The majority of patients presented during the late course of their disease process and had a moderate hearing loss. Improvement of air conduction threshold and $A B$ gap after type I tympanoplasty was statistically significant. Thus from this study it can be concluded that type I tympanoplasty is an effective technique for hearing improvement in inactive mucous type of chronic otitis media.

\section{References}

1) WHO Project: ICP DPR 2001, 'Development of framework of proposed regional collaboration for prevention of deafness and hearing impairment. Report of an intercountry meeting, Bangkok, Thailand, November 2003', WHO New Delhi; March 2004: 2.

2) World Health Organization. (2008). The global burden of disease: 2004 update. Geneva: World
Health Organization. Retrieved from http://www.who.int/healthinfo/global_burdendise ase/GBD_report_2004update_full.pdf.

(Accessed 18th August 2014).

3 ) World health organization regional office for south-east Asia, 1985: State of hearing \& ear care in the South East Asia region. chapter-1, page-7.

4) World Health Organization, 2010. Deafness and Hearing Impairment. Retrieved from http://www.who.int/mediacentre/factsheet/fs300.

(Accessed 18th August 2014).

5) Smith A and Mathers C 2006, 'Epidemiology of infection as a cause of hearing loss', In V. E. Newton \& P. J. Vallely (Eds.). Infection and hearing impairment. England: John Wiley \& Sons, pp. 31-66.

6) Ludman H, 1998, 'Reconstruction's of the middle ear', Mawson's Diseases of the ear, $6^{\text {th }}$ ed. Edward Arnold, London, 1998; 429-38.

7) Swanepoel D. Infant hearing loss in developing countries: A silent health priority', Audiology Today 2008; 20:108-132

8) Pickles JO, 2008 Physiology of hearing. Scott-Brown's Otorhinolaryngology, Head \& Neck Surgery.chapter-229, $7^{\text {th }}$ ed. Edward Arnold: Great Britain, vol.5, pp. 3184.

9) Browning GG, 1997, 'Aetiopathology of inflammatory conditions of the middle ear', In: Kerr AG, editor. Scott Brown's otolaryngology, $6^{\text {th }}$ edition. vol. 3, Arnold, London, pp. 33963404.

10) Mills RP 1997, 'Management of chronic suppurative otitis media', In: Booth JB, editor. Scott Brown's otolaryngology, $6^{\text {th }}$ edition. vol. 3 , London: Butterworths, p. 3102.

11) Joshi RR, Jha AK, Rijal AS, Dhungana $A$ and Shrestha KK, Hearing evaluation after myringoplasty at Nepal Medical College and Teaching hospital Journal 2013; 2:36-42

12) Bluestone C. Myringoplasty and tympanoplasty, 2011. In: RM Rosenfeld \& CD Bluestone; Evidence based otitis media. USA: BC Decker Inc.

13) Tai CF, Ho KY and Juan KH. Age and the prognosis of tympanoplasty type I. Kao Hsiung I Hsueh Ko Hsueh Tsa Chih1999; 14:542-47

14) Biswas SS, Hossain A, Alam M, Atiq T and Al-Amin $Z$. 'Hearing evaluation after 
myringoplasty', Bangladesh J Otorhinolaryngol 2011; 16:23-28.

15) Islam $T$, Rashid HA, Ali MI and Haque $M$. The outcomes of myringoplasty. Bangladesh $\mathrm{J}$ Otorhinolaryngol, 2013; 19: 202-9

16) Alam KMN, Ali MI, Huq $M$ and Hanif $A$, 2013, 'Prognostic factors influencing anatomical and functional outcome of Myringoplasty', Bangladesh J Otorhinolaryngol, vol. 19, no. 1, pp. 18-23.

17) Shetty S, 2012, 'Pre-Operative and PostOperative Assessment of Hearing following Tympanoplasty', Indian J Otolaryngol Head Neck Surg, vol. 64, no. 4, pp. 377-381.

18) Krishna PH and Devi TS. Clinical Study of Influence of Prognostic Factors on the Outcome of Tympanoplasty .IOSR Journal of Dental and Medical Science Sur2013; 5: 41-45.

19) Sarker MZ, Ahmed M, Patwary K, Islam R, Joarder AH. Factors Affecting Surgical Outcome of Myringoplasty. Bangladesh Medical Journal2012; vol. 41(3): 45-48.

20) Lee P, Kelly G and Mills RP. Myringoplasty: does the size of perforation matter? Clinical Otolaryngology and Allied Sciences 2012; 27: 331-334.

21) Palva $T$ and Ramsay $H$. Myringoplasty and tympanoplasty-results related to training and experience. Clinical Otolaryngology and Allied Sciences 1995; 20: 329-35.

22) Mehta K, Sinha V, Chhaya VA, Barot DA, Patel P, Patil S, 2009, 'Audiometric and Operative Results in Type I Tympanoplasty', Available from:

http://www.waent.org/archives/2009/vol22/20091115-audiology/audiology-chronic-eardisease.htm

23) Vaidya S, Sharma JK and Singh G. Study of Outcome of Tympanoplasties in Relation to Size and Site of Tympanic Membrane Perforation. Indian J Otolaryngol Head Neck Surg 2015; 66(3): 341-346.
24) Shrestha $S$ and Sinha BK. Hearing results after myringoplasty', Kathmandu Univ Med J 2006; 4:55-9.

25) Palukuri S and Raju VG. One Year Follow up Study on Audiological Profile in Chronic Otitis Media Patients, After Type 1 Tympanoplasty. International Journal of Recent Trends in Science and Technology 2014; 9(3): 343-345. 